\title{
Large coronary aneurysm may indicate concomitant asymptomatic huge thoracic aortic aneurysm
}

\author{
Ahmet Karabulut* \\ Department of Cardiology, Acıbadem University School of Medicine, Aclbadem Atakent Hospital, Istanbul, Turkey
}

\section{A R T I C L E I N F O}

\section{Article history:}

Received 28 April 2016

Accepted 30 May 2016

Available online 2 June 2016

\section{Keywords:}

Aneurysm

Coronary

Thoracic aorta

Silent progression

\begin{abstract}
A B S T R A C T
Simultaneous aneurysms of coronary vessels and aorta were rarely reported with an involvement of abdominal aorta. Co-incidence of isolated thoracic aortic aneurysm (TAA) and coronary aneurysm is not known. Herein, we presented a silent TAA presented with aortic dissection. Previously performed coronary angiography via right radial route revealed large coronary aneurysm with a diameter of $12 \mathrm{~mm}$. Ascending aorta was evaluated as normal size with echocardiography. "Clinical intuition" might be the only way to seek and detect asymptomatic TAA. Diffuse atherosclerotic coronary heart disease with coronary aneurysm should be an impulse to screen asymptomatic aortic aneurysms.

(c) 2016 The Society of Cardiovascular Academy. Production and hosting by Elsevier B.V. All rights reserved. This is an open access article under the CC BY-NC-ND license (http://creativecommons.org/licenses/by-nc-nd/4.0/).
\end{abstract}

\section{Introduction}

Simultaneous aneurysms of coronary vessels and aorta were rarely reported with an involvement of abdominal aorta. Co-incidence of isolated thoracic aortic aneurysm (TAA) and coronary aneurysm is not known. Herein, we presented a silent TAA presented with aortic dissection which also possesses large coronary artery aneurysm. We think that, extensive coronary artery atherosclerosis and large coronary aneurysm may strongly indicate silent isolated TAA.

\section{Case report}

A 67 year-old male patient admitted emergency department with a complaint of severe claudication in the right leg. Previously performed coronary angiography via right radial route revealed large coronary aneurysm with a diameter of $12 \mathrm{~mm}$ (Fig. 1). Ascending aorta was evaluated as normal size with echocardiography in last presentation. Computed tomography performed in the final presentation showed a large dissected $6.6 \mathrm{~cm}$ TAA beginning from the osteum of left common carotid artery and extending beyond the left subclavian artery (Fig. 2). Dissection flap was began within the aneurysm and extend to right iliac arteries. Patient had been followed with a diagnosis of CAD for 7 years and coronary angiography performed 7 years ago also

\footnotetext{
* Acıbadem University Atakent Hospital, Department of Cardiology, Halkalı Merkez Mah, Turgut Özal Bulvarı, No:16, 34303, Kucukcekmece, Istanbul, Turkey. Tel.: + 90 5053577477; fax: +902124044445.

E-mail address: drkarabulut@yahoo.com.

Peer review under responsibility of The Society of Cardiovascular Academy.
}

revealed coronary aneurysm. Aortic pathology was progressed silently until dissection formation occurred. Hybrid therapy consisting of debranching operation and endovascular repair was scheduled for the patients.

\section{Discussion}

Coronary aneurysms are not uncommon with a frequency of $1-4 \%$ in routine autopsies or coronary angiographies. ${ }^{1-2}$ Hovewer, giant coronary aneurysms are rarely reported in the medical literature. In adults, atherosclerosis is a main factor for progression of coronary aneurysms and clinical presentation can variate. ${ }^{1-2}$ Diffuse and advanced atherosclerotic involvement of coronary vessels are associated with other vascular pathology including aortic diseases. ${ }^{3-4}$ Aortic aneurysms usually observed in the elderly men with predominantly abdominal involvement. Advanced atherosclerotic process and weakening of medial layer are proposed major pathophysiologic mechanism for aortic aneurysm. Abdominal aortic aneurysms (AAA) are frequently associated with various forms of coronary artery disease. Approximately $80 \%$ of patients with AAA will have angiographic evidence of atherosclerosis in at least one coronary vessel and nearly $20 \%$ percent of all AAA patients will have surgically treatable coronary artery disease. Whereas, the incidence of aortic aneurysms among patients with coronary artery disease (CAD) is $4.4 \%$ to $7 \%{ }^{3}$ Furthermore, significant aortoiliac artery aneurysm was associated with CAD in $90 \%$ of patients, while it's prevalence was directly correlated with the severity of CAD being depicted in $40.2 \%$ of patients with three-vessel disease or more. Multivessel CAD (three-vessel disease or more), age older than 60 years, and three or more risk factors were revealed as independent predictors of abdominal vessel stenosis or aneurysm. 


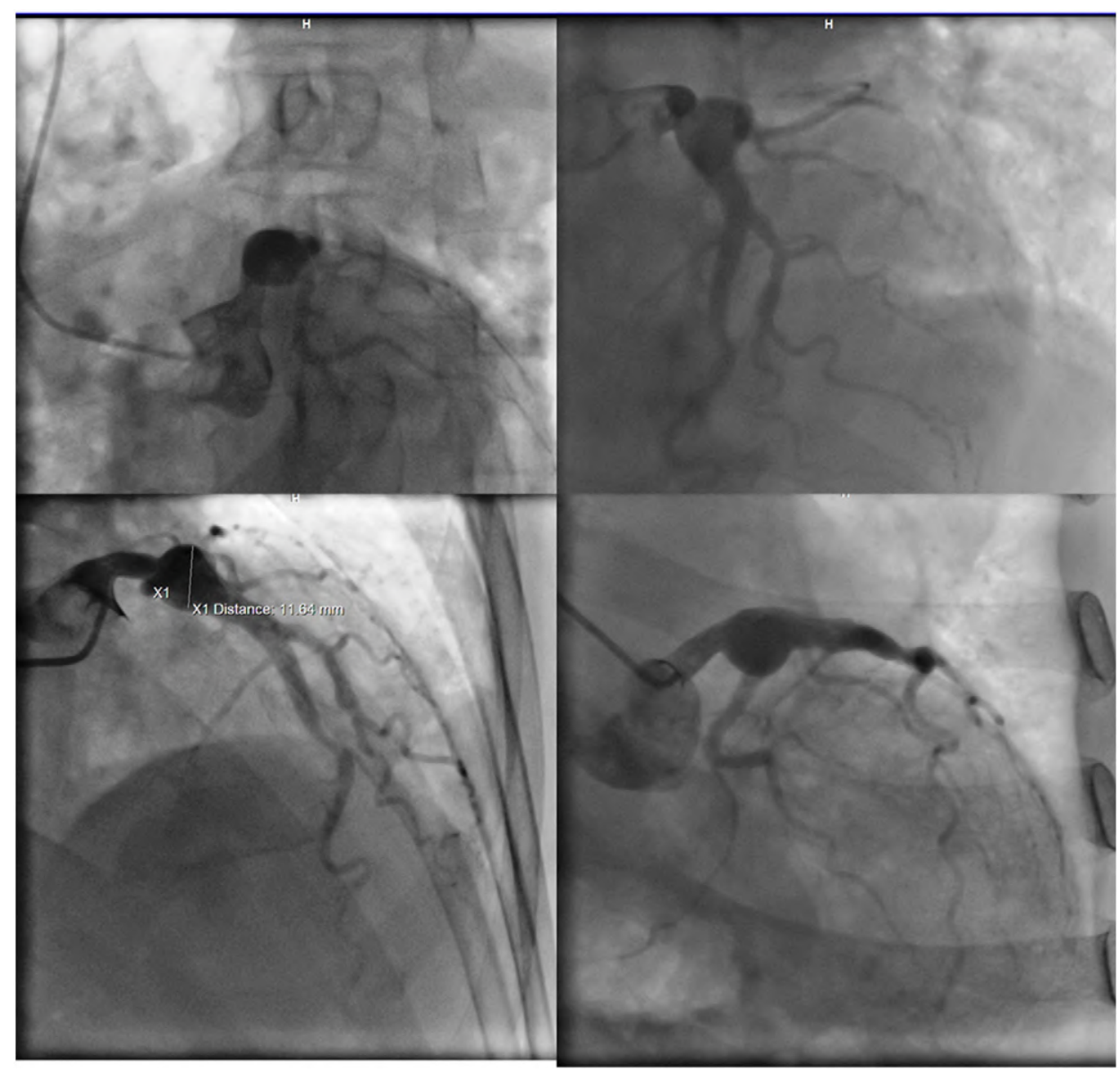

Fig. 1. Large coronary aneurysm extending between distal left main coronary artery and proximal left anterior descending artery.

Isolated thoracic aortic aneurysm (TAA) is rare situation and majority diagnosed either incidentally or catastrophic clinical presentation with dissection or rupture. Association of CAD and coronary aneurysm with TAA was not well-defined. ${ }^{5}$ In addition, simultaneous aneurysms of coronary vessels and aorta were rarely reported with an involvement of abdominal aorta. Co-incidence of isolated TAA and coronary aneurysm is not known. We thought that, extensive coronary artery atherosclerosis and large coronary aneurysm may strongly indicate silent isolated TAA. Further epidemiologic studies may clarify our speculation.

\section{Conclusion}

Thoracic aortic aneurysm usually progress without symptom which make difficult to earlier definite diagnosis. "Clinical intuition" might be the only way to seek and detect asymptomatic TAA. Large coronary aneurysms are usually associated with diffuse and accelerated atherosclerotic process which may indicate concomitant silent TAA. Routine screening of such patient facilitate earlier diagnosis of TAA and prevent mortal complication including dissection and rupture.

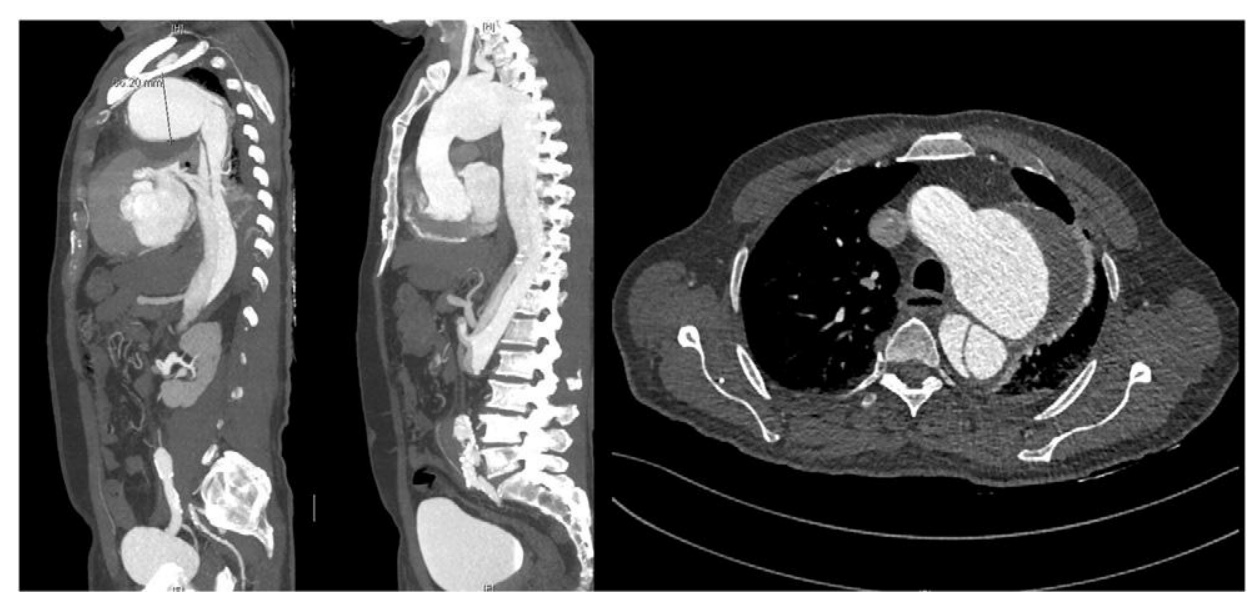

Fig. 2. Computed tomographic aortography showing huge dissected thoracic aortic aneurysm. 


\section{References}

1. Mariscalco G, Mantovani V, Ferrarese S, Leva C, Orru A, Sala A. Coronary artery aneurysm: management and association with abdominal aortic aneurysm. Cardiovasc Pathol 2006;15(2):100-104

2. Cebeci BS, Yiğiner O, Kardeşoğlu E, et al. Two giant coronary artery aneurysms accompanying aortic aneurysms. Anadolu Kardiyol Derg 2011;1:E1-E5.

3. Rigatelli G, Rigatelli G. Vascular profile of patients with multivessel coronary artery disease. Int J Cardiol 2006;106(1):35-40.
4. Andreou AY, Avraamides PC, Georgiou GM. A patient with multiple vascular atherosclerotic distributions. Exp Clin Cardiol 2011;16(1):27-29.

5. Erbel R, Aboyans V, Boileau C, et al. 2014 ESC guidelines on the diagnosis and treatment of aortic diseases: document covering acute and chronic aortic diseases of the thoracic and abdominal aorta of the adult. The Task Force for the Diagnosis and Treatment of Aortic Diseases of the European Society of Cardiology (ESC). Eur Heart J 2014;35(41):2873-2926. 